\title{
Efficacy and safety of nitazoxanide plus atazanavir/ritonavir for the treatment of moderate to severe COVID-19 (NACOVID): A structured summary of a study protocol for a randomised controlled trial
}

\author{
Adeniyi Olagunju ${ }^{1,2^{*}}$ (D) Adeola Fowotade ${ }^{3}$, Ajibola Olagunoye ${ }^{4}$, Temitope Olumuyiwa Ojo ${ }^{5}$,
} Bolanle Olufunlola Adefuye ${ }^{6}$, Adeniyi Francis Fagbamigbe ${ }^{7}$, Akindele Olupelumi Adebiyi ${ }^{8}$, Omobolanle Ibitayo Olagunju ${ }^{9}$, Olabode Taiwo Ladipo ${ }^{10}$, Abdulafeez Akinloye ${ }^{1}$, Babatunde Ayodeji Adeagbo ${ }^{1}$, Adedeji Onayade ${ }^{5}$, Oluseye Oladotun Bolaji ${ }^{1}$, Christian Happi ${ }^{11}$, Steve Rannard ${ }^{12}$ and Andrew Owen ${ }^{2}$

\footnotetext{
Abstract

Objectives: To investigate the efficacy and safety of repurposed antiprotozoal and antiretroviral drugs, nitazoxanide and atazanavir/ritonavir, in shortening the time to clinical improvement and achievement of SARS-CoV-2 polymerase chain reaction (PCR) negativity in patients diagnosed with moderate to severe COVID-19.

Trial design: This is a pilot phase 2, multicentre 2-arm (1:1 ratio) open-label randomised controlled trial. Participants: Patients with confirmed COVID-19 diagnosis (defined as SARS-CoV-2 PCR positive nasopharyngeal swab) will be recruited from four participating isolation and treatment centres in Nigeria: two secondary care facilities (Infectious Diseases Hospital, Olodo, Ibadan, Oyo State and Specialist State Hospital, Asubiaro, Osogbo, Osun State) and two tertiary care facilities (Obafemi Awolowo University Teaching Hospitals Complex, Ile-Ife, Osun State and Olabisi Onabanjo University Teaching Hospital, Sagamu, Ogun State). These facilities have a combined capacity of 146-bed COVID-19 isolation and treatment ward.

(Continued on next page)
}

\footnotetext{
* Correspondence: aeolagunju@oauife.edu.ng

${ }^{1}$ Department of Pharmaceutical Chemistry, Faculty of Pharmacy, Obafemi Awolowo University, Ile-Ife, Nigeria

2Department of Molecular and Clinical Pharmacology, University of Liverpool, Liverpool, United Kingdom

Full list of author information is available at the end of the article
}

(c) The Author(s). 2021 Open Access This article is licensed under a Creative Commons Attribution 4.0 International License, which permits use, sharing, adaptation, distribution and reproduction in any medium or format, as long as you give appropriate credit to the original author(s) and the source, provide a link to the Creative Commons licence, and indicate if changes were made. The images or other third party material in this article are included in the article's Creative Commons licence, unless indicated otherwise in a credit line to the material. If material is not included in the article's Creative Commons licence and your intended use is not permitted by statutory regulation or exceeds the permitted use, you will need to obtain permission directly from the copyright holder. To view a copy of this licence, visit http://creativecommons.org/licenses/by/4.0/. The Creative Commons Public Domain Dedication waiver (http://creativecommons.org/publicdomain/zero/1.0/) applies to the data made available in this article, unless otherwise stated in a credit line to the data. 
(Continued from previous page)

Inclusion criteria: Confirmation of SARS-COV-2 infection by PCR test within two days before randomisation and initiation of treatment, age bracket of 18 and 75 years, symptomatic, able to understand study information and willingness to participate. Exclusion criteria include the inability to take orally administered medication or food, known hypersensitivity to any of the study drugs, pregnant or lactating, current or recent (within 24 hours of enrolment) treatment with agents with actual or likely antiviral activity against SARS-CoV-2, concurrent use of agents with known or suspected interaction with study drugs, and requiring mechanical ventilation at screening.

Intervention and comparator: Participants in the intervention group will receive 1000 mg of nitazoxanide twice daily orally and 300/100 mg of atazanvir/ritonavir once daily orally in addition to standard of care while participants in the control group will receive only standard of care. Standard of care will be determined by the physician at the treatment centre in line with the current guidelines for clinical management of COVID-19 in Nigeria.

Main outcome measures: Main outcome measures are: (1) Time to clinical improvement (defined as time from randomisation to either an improvement of two points on a 10-category ordinal scale (developed by the WHO Working Group on the Clinical Characterisation and Management of COVID-19 infection) or discharge from the hospital, whichever came first); (2) Proportion of participants with SARS-CoV-2 polymerase chain reaction (PCR) negative result at days 2, 4, 6, 7, 14 and 28; (3) Temporal patterns of SARS-CoV-2 viral load on days 2, 4, 6, 7, 14 and 28 quantified by RT-PCR from saliva of patients receiving standard of care alone versus standard of care plus study drugs.

Randomisation: Allocation of participants to study arm is randomised within each site with a ratio 1:1 based on randomisation sequences generated centrally at Obafemi Awolowo University. The model was implemented in REDCap and includes stratification by age, gender, viral load at diagnosis and presence of relevant comorbidities.

Blinding: None, this is an open-label trial.

Number to be randomised (sample size): 98 patients (49 per arm).

Trial status: Regulatory approval was issued by the National Agency for Food and Drug Administration and Control on 06 October 2020 (protocol version number is 2.1 dated 06 August 2020). Recruitment started on 9 October 2020 and is anticipated to end before April 2021.

Trial registration: The trial has been registered on ClinicalTrials.gov (July 7, 2020), with identifier number NCT0445 9286 and on Pan African Clinical Trials Registry (August 13, 2020), with identifier number PACTR202008855701534.

Full protocol: The full protocol is attached as an additional file which will be made available on the trial website. In the interest of expediting dissemination of this material, the traditional formatting has been eliminated, and this letter serves as a summary of the key elements in the full protocol.

The study protocol has been reported in accordance with the Standard Protocol Items: Recommendations for Clinical Interventional Trials (SPIRIT) guidelines (Additional file 2).

Keywords: COVID-19, SARS-CoV-2, nitazoxanide, atazanavir/ritonavir, randomised controlled trial, protocol

\section{Supplementary Information}

The online version contains supplementary material available at https://doi. org/10.1186/s13063-020-04987-8

Additional file 1. Full Study Protocol.

Additional file 2. SPIRIT 2013 Checklist: Recommended items to address in a clinical trial protocol and related documents.

\section{Acknowledgement}

We acknowledge the support of the management of the participating hospitals in Ogun, Osun, and Oyo States for permission to recruit patients from their isolation and treatment centres.

\section{Authors' contributions}

AdOI and AdOw: study conception and design, protocol writing. All authors contributed to the review of the protocol, approved the submitted version and writing of this submission. The authors read and approved the final manuscript.

\section{Funding}

This trial is funded by a grant from the University of Liverpool, United Kingdom. The funder had no role in the design of this study and will not have any role during its execution, analyses, interpretation of the data, or decision to submit results.

\section{Availability of data and materials}

Trial data are available to the investigators through the Obafemi Awolowo University REDCap web platform. Summary data will be made open access. However, requests for access to disaggregated and anonymised data will be assessed on a case by case basis, depending on the qualifications of the requester, quality of request and type of secondary analysis proposed.

\section{Ethics approval and consent to participate}

Ethics approvals were issued by the National Health Research Ethics Committee, Nigeria on 26 August 2020 (approval number: NHREC/01/01/ 2007-26/08/2020) and the University of Liverpool Health and Life Sciences Research Ethics Committee on 29 September 2020 (reference number: 8074). We certify that the study was approved by the ethics committees as described above. Informed consent will be obtained from the participants 
after they have been given adequate information about the study (including objectives, methods, procedures, risks and benefits) in simple, clear and understandable words. This is being managed electronically using REDCap.

\section{Consent for publication}

Not applicable.

\section{Competing interests}

The authors declare that there is no competing interest related to the protocol.

\section{Author details}

'Department of Pharmaceutical Chemistry, Faculty of Pharmacy, Obafemi Awolowo University, lle-Ife, Nigeria. ${ }^{2}$ Department of Molecular and Clinical Pharmacology, University of Liverpool, Liverpool, United Kingdom.

${ }^{3}$ Department of Medical Microbiology and Parasitology, College of Medicine, University of Ibadan, Ibadan, Nigeria. ${ }^{4}$ State Specialist Hospital, Osogbo, Nigeria. ${ }^{5}$ Department of Community Health, Faculty of Clinical Sciences, Obafemi Awolowo University Teaching Hospital, lle-lfe, Nigeria. ${ }^{6}$ Olabisi Onabanjo University Teaching Hospital, Sagamu, Nigeria. ${ }^{7}$ Department of Epidemiology and Medical Statistics, Faculty of Public Health, University of Ibadan, Ibadan, Nigeria. ${ }^{8}$ Department of Community Medicine, University of Ibadan, Ibadan, Nigeria. 'Department of Surveillance and Epidemiology, Nigeria Centre for Disease Control, Abuja, Nigeria. ${ }^{10}$ Oyo State Ministry of Health, Ibadan, Nigeria. ${ }^{11}$ African Centre of Excellence for Genomics of Infectious Diseases, Redeemer's University, Ede, Nigeria. ${ }^{12}$ Department of Chemistry, School of Physical Sciences, University of Liverpool, Liverpool, United Kingdom.

Received: 14 December 2020 Accepted: 18 December 2020

Published online: 04 January 2021

\section{Publisher's Note}

Springer Nature remains neutral with regard to jurisdictional claims in published maps and institutional affiliations.

Ready to submit your research? Choose BMC and benefit from:
- fast, convenient online submission
- thorough peer review by experienced researchers in your field
- rapid publication on acceptance
- support for research data, including large and complex data types
- gold Open Access which fosters wider collaboration and increased citations
- maximum visibility for your research: over 100M website views per year
At BMC, research is always in progress.
Learn more biomedcentral.com/submissions

